\title{
Effects of Rhododendron removal on soil bacterial and fungal communities in southern Appalachian forests
}

\author{
Ernest D. Osburn $^{\mathrm{a}, *}$, Chelcy F. Miniat ${ }^{\mathrm{b}, \mathrm{c}}$, Katherine J. Elliott ${ }^{\mathrm{b}}$, J.E. Barrett ${ }^{\mathrm{a}}$ \\ ${ }^{\text {a }}$ Department of Biological Sciences, Virginia Polytechnic Institute and State University, Blacksburg, VA, USA \\ ${ }^{\mathrm{b}}$ USDA Forest Service Coweeta Hydrologic Laboratory, 3160 Coweeta Lab Road, Otto, NC 28763, United States \\ c USDA Forest Service, Rocky Mountain Research Station, Albuquerque, NM 87102, United States
}

\section{A R T I C L E I N F O}

\section{Keywords:}

Microbial community

$16 \mathrm{~S}$

ITS

Diversity

Mycorrhizal fungi

Sequencing

\begin{abstract}
A B S T R A C T
Rhododendron maximum, a native ericaceous evergreen shrub, is expanding in forests of the southern Appalachian region following eastern hemlock (Tsuga canadensis) mortality due to hemlock woolly adelgid (Adelges tsugae) infestations. The goal of our study was to examine soil microbial community responses to experimental $R$. maximum removal treatments. The experiment was implemented as a $2 \times 2$ factorial design, including two $R$. maximum canopy removal levels (cut vs. not cut) combined with two forest floor removal levels (burned vs. not burned). These treatments were designed as potential management strategies to facilitate hardwood tree establishment in forests that have experienced T. canadensis declines. We sampled soils after removals and characterized bacterial and fungal communities using amplicon sequencing. Shrub removal did not affect bacterial or fungal $\alpha$ diversity but did affect both bacterial and fungal community composition. Relative abundances of bacterial phyla and fungal classes exhibited no differences among $R$. maximum removal treatments. However, specific bacterial and fungal taxa that were responsive to $R$. maximum removal (i.e., differentially abundant sequences) did exhibit clear patterns at high taxonomic levels. Specifically, taxa that responded negatively to $R$. maximum removal were found primarily in two bacterial phyla (Proteobacteria and Bacteroidetes) and one fungal class (Archaeorhizomycetes) while positive responders were clustered in several other bacterial phyla (e. g., Actinobacteria, Planctomycetes, Cyanobacteria). Fungal functional guilds also responded to R. maximum removal, including negative responses of ericoid mycorrhizae and positive responses of arbuscular mycorrhizae and wood saprotrophs. Effects of $R$. maximum removal on soil microbial communities were minor overall, but clear effects on some key functional groups were evident (i.e., mycorrhizal fungi), suggesting that microbial responses to $R$. maximum removal may influence recovery of forests in the southern Appalachian region.
\end{abstract}

\section{Introduction}

Rosebay rhododendron (Rhododendron maximum L.), a native ericaceous evergreen woody shrub, is the dominant understory species in moist cove and riparian forests of the southern Appalachian region. This shrub influences forest ecosystem structure and function within these mesic habitats in numerous ways. For example, $R$. maximum reduces soil temperature and moisture (Cofer et al., 2018) and recalcitrant $R$. maximum leaf litter suppresses organic matter decomposition rates in the forest floor (Ball et al., 2008; Hunter et al., 2003). In addition, $R$. maximum reduces availability of soil nitrogen $(\mathrm{N})$, as $R$. maximumderived organic $\mathrm{N}$ is preferentially immobilized by $R$. maximum's own ericoid mycorrhizal symbionts (Wurzburger and Hendrick, 2009, 2007).
These alterations to soil properties and processes, along with attenuation of light by the dense $R$. maximum subcanopy, inhibits recruitment of hardwood tree seedlings, thereby influencing forest dynamics (Beckage et al., 2000; Clinton, 2003; Nilsen et al., 2001). Indeed, canopy trees are on average $6 \mathrm{~m}$ shorter in areas where $R$. maximum is present than in areas where it is absent (Bolstad et al., 2018), illustrating the potential for $R$. maximum to influence forest ecosystems at the landscape scale.

In the past century, $R$. maximum has expanded in southern Appalachian forests, initially due to early 20th Century die-offs of American chestnut (Castanea dentata (Marsh) Borkh) (Elliott and Vose, 2012) and more recently due to declines of eastern hemlock (Tsuga canadensis (L.) Carrière) following hemlock woolly adelgid (Adelges tsugae Annand) infestations (Ford et al., 2012). This expansion of R. maximum, along

\footnotetext{
* Corresponding author at: Virginia Tech Department of Biological Sciences, 2125 Derring Hall 926 West Campus Drive, Blacksburg, VA 24061, United States.

E-mail address: eosburn@vt.edu (E.D. Osburn).
} 
with the dominant role of $R$. maximum in structuring forest ecosystems, suggests that southern Appalachian forests are undergoing fundamental changes in the years following eastern hemlock declines. In response, forest managers have suggested aggressive $R$. maximum removal strategies to promote recovery of southern Appalachian forests that have experienced hemlock die-offs (Vose et al., 2013). These removal strategies include mechanical cutting of the $R$. maximum subcanopy, application of herbicide to stumps to prevent re-sprouting, and low intensity prescribed fire to remove the thick forest floor that develops underneath $R$. maximum thickets (Vose et al., 2013). Here, we focus on influences of these $R$. maximum removal strategies on soil bacterial and fungal communities. Because soil microorganisms facilitate virtually all ecosystem processes, particularly biogeochemical cycling of soil nutrients (Falkowski et al., 2008; Fierer, 2017), microbial community responses to $R$. maximum removal are likely to be key drivers of forest recovery following removal treatments.

Prior studies have reported numerous effects of forest understory removal on soil microbial communities, including increased dominance of bacteria relative to fungi and altered production of microbial extracellular enzymes (Boerner et al., 2008; Giai and Boerner, 2007; Shen et al., 2018; Wu et al., 2011; Zhao et al., 2011). In contrast, a prior experimental $R$. maximum subcanopy removal in the southern Appalachians revealed no evident effects on soil biota, including no changes in microbial biomass or invertebrate communities (Wright and Coleman, 2002), though that prior study was not replicated and was confounded by a hurricane that extensively disturbed the reference plot. Additionally, experimental removal of $R$. ponticum in the UK revealed no effects of canopy removal on microbial community structure (Jones et al., 2019). Together, these studies suggest that forest understory removal in general can influence soil microorganisms, but that $R$. maximum canopy removal alone may not be sufficient to alter soil bacterial and fungal communities. This lack of biotic response to shrub removal alone is potentially attributed to the continued influence of the thick Rhododendron leaf litter layer, which likely limits availability of soil resources (e.g., soil N) to soil microorganisms. Therefore, forest floor removal in addition to $R$. maximum shrub removal may also be necessary to elicit soil biotic responses.

The goal of our study was to determine microbial community responses to experimental $R$. maximum canopy removal in combination with forest floor (i.e., O-horizon) removal. A previous study from this same experiment showed that $R$. maximum removal altered forest vegetation, including increased cover and diversity of herbaceous vegetation and increased density of tree seedings (Elliott and Miniat, 2018). In addition, these changes in vegetation were accompanied by increased soil $\mathrm{C}$ and $\mathrm{N}$, increased total microbial biomass, and increased activities of microbial extracellular enzymes (Osburn et al., 2018). However, influences on soil bacteria and fungi at the community level are unknown. In general, we predicted that altered soil characteristics and vegetation communities would drive changes in overall soil bacterial and fungal community structure following $R$. maximum removal. Specifically, we predicted that increased soil $\mathrm{C}$ and $\mathrm{N}$ availability would result in increased relative abundance of bacterial taxa that grow rapidly and have high nutrient demands (i.e., r-selected taxa) and increased relative abundance of nitrifying bacteria. Further, we predicted that changes in vegetation following $R$. maximum removal would be reflected in the relative abundances of fungal functional groups, with reduced abundance of $R$. maximum symbionts (i.e., ericoid mycorrhizae) and increased abundance of tree and herb symbionts (e.g., arbuscular and ectomycorrhizae).

\section{Materials and methods}

\subsection{Site description}

We conducted this study at the Coweeta Hydrologic Lab $\left(35^{\circ} 03^{\prime} \mathrm{N}\right.$, $83^{\circ} 25^{\prime} \mathrm{W}$ ), a USDA Forest Service experimental forest. Coweeta is located in the Nantahala Mountain range of western North Carolina within the Blue Ridge physiographic province of the southern Appalachian Mountains. Mean annual temperature at Coweeta is $12.6^{\circ} \mathrm{C}$ and ranges seasonally from 3.3 to $21.6^{\circ} \mathrm{C}$. Rainfall is generally abundant at Coweeta, averaging $\sim 1800 \mathrm{~mm}$ per year (Laseter et al., 2012). Soils are deep, sandy loams and two soil orders are present within our study sites: Inceptisols and Ultisols in the Cullasaja-Tuckasegee and EdneyvilleChestnut complexes, respectively (Thomas, 1996). Soils within our sites are characterized by high organic matter in the A horizon and a clay-accumulating B horizon. Within the Coweeta basin, we selected areas in mesic, riparian areas previously dominated by $T$. canadensis ( $>50 \%$ basal area), all of which were dead at the time of study. Living overstory trees in the selected sites included Acer rubrum L., Liriodendron tulipifera L., Betula lenta L., Quercus montana Willd., Quercus rubra L., and Carya spp. Selected study areas had low-to-moderate slopes $(<30 \%)$, were at elevations ranging from 760 to $1060 \mathrm{~m}$, and had R. maximum densities averaging $7325 \mathrm{stems} \mathrm{ha} \mathrm{ha}^{-1}$ and basal areas averaging $7.36 \mathrm{~m}^{2}$ $\mathrm{ha}^{-1}$ (Elliott and Miniat, 2018).

\subsection{Experimental design and soil sampling}

We applied $R$. maximum removal treatments to sixteen $20 \mathrm{~m} \times 20 \mathrm{~m}$ (0.04 ha) plots located in the Coweeta Basin. The four treatments included R. maximum canopy removal (hereafter, CR), soil O-horizon removal (hereafter, FF), both canopy and O-horizon removal (hereafter, CFFR), and no removal (hereafter, REF). Each treatment was replicated four times and treatments were randomly assigned to the sixteen plots. In the CR and CFFR treatments, the $R$. maximum canopy was manually cut, following which cut material was either further slashed to the ground not to exceed $1.2 \mathrm{~m}$ in height (CFFR) or piled just outside the treatment area (CR). Herbicide was applied to cut stumps to prevent resprouting. The herbicide was a triclopyr amine (Garlon $3 \mathrm{~A} \otimes$, DOW Agrosciences) formulation with an aquatic label (50\% triclopyr amine/ $50 \%$ water). Rhododendron maximum cutting (CR, CFFR) was performed in March-May 2015. The FF and CFFR treatments involved low-intensity prescribed fires to remove the thick forest floor (i.e., O horizon) that develops beneath R. maximum. Burning took place in March 2016 and followed the USDA Forest Service, Nantahala National Forest Prescribed Burning Plan (USDA, 2011). The fires resulted in temporary removal of the Oi (leaf litter) layer but did not consume the Oe + Oa layers (Elliott and Miniat, 2018).

To characterize pre-treatment soil microbial communities, in July 2014, we sampled three A horizon $(0-10 \mathrm{~cm})$ soil cores from each plot, and composited samples by plot. We then repeated soil sampling in April and July 2017, two years following $R$. maximum canopy removal and one year following forest floor (Oi only) removal. Soil subsamples were stored at $-20{ }^{\circ} \mathrm{C}$ prior to DNA extraction and $4{ }^{\circ} \mathrm{C}$ prior to measurement of soil chemical properties. Chemical properties, i.e., dissolved organic $\mathrm{C}$ (DOC), total dissolved $\mathrm{N}(\mathrm{TDN}), \mathrm{NO}_{3}^{-}, \mathrm{NH}_{4}^{+}$, and $\mathrm{pH}$ were measured according to previously described methods (Osburn et al., 2018), and these data are provided on Table S1. As previously reported, soils where $R$. maximum was removed (especially CFFR) exhibited larger DOC, TDN, $\mathrm{NO}_{3}^{-}$, and $\mathrm{NH}_{4}^{+}$pools compared with REF soils (Table S1) (Osburn et al., 2018).

\subsection{DNA extraction, PCR, and amplicon sequencing}

We characterized soil microbial communities using a DNA sequencing approach, beginning with isolation of DNA from soil. We extracted DNA from $0.25 \mathrm{~g}$ of each soil sample using the Qiagen DNaasy PowerSoil kit (Qiagen, Valencia, CA) and quantified extracts using a Qubit 2.0 fluorometer (Thermo Fisher Inc., Waltham, MA, USA). We characterized bacterial communities by PCR-amplifying and sequencing the V4 region of the 16S rRNA gene using the 515f/806r primer pair (Apprill et al., 2015; Parada et al., 2016), while for fungi we amplified and sequenced the ITS1 ribosomal region using the ITS1f/2 primer pair 
(Bellemain et al., 2010). The 16 S and ITS1 regions serve as marker genes for bacteria and fungi, respectively, allowing for taxonomic identification of sequences. Each PCR reaction contained $10 \mu \mathrm{l}$ Thermo Fisher Platinum II Hot Start PCR Master Mix (Thermo Fisher Inc, Waltham, MA, USA), $1 \mu$ DNA template, $0.2 \mu \mathrm{M}$ forward and reverse primers, and nuclease-free $\mathrm{H}_{2} \mathrm{O}$ to $25 \mu \mathrm{l}$. All samples were amplified in triplicate under previously described thermal cycling conditions (Osburn et al., 2019). After amplification, we pooled triplicate reactions and visualized PCR products on a $1 \%$ agarose gel. We then used a Qiagen QIAquick PCR Purification Kit (Qiagen, Valencia, CA, USA) to purify amplicons, quantified the purified amplicons, and pooled 16S and ITS amplicons separately in equimolar ratios. Amplicons were sequenced on the Illumina MiSeq platform using 250 bp paired end reads. Raw sequence reads were deposited in NCBI's BioProject database under accession number PRJNA548911.

\subsection{Bioinformatic processing}

We processed raw sequences in QIIME2 (Bolyen et al., 2018) using the DADA2 pipeline (Callahan et al., 2016). After DADA2 processing, we retained 5,369,291 bacterial 16S rDNA sequences and 842,044 fungal ITS sequences for further processing. We then rarefied the $16 \mathrm{~S}$ and ITS data sets to 23,019 and 3,774 sequences per sample, respectively, to account for differences in sequencing depth among samples. Rarefaction was performed using the 'rarefy_even_depth' function of the phyloseq $\mathrm{R}$ package (McMurdie and Holmes, 2013). After rarefying, we retained 7,875 bacterial amplicon sequence variants (ASVs) and 1,530 fungal ASVs for downstream analyses. Each ASV is a unique 16S or ITS DNA sequence identified by the DADA2 algorithm. We assigned taxonomy to ASVs using a naïve-bayes classifier (Pedregosa et al., 2011) trained on the Greengenes (version 13.8) and UNITE (version 8.2) databases for bacteria and fungi, respectively (Abarenkov et al., 2010; McDonald et al., 2012). To assess effects of $R$. maximum removal on bacterial life history strategies, we categorized abundant bacterial phyla as either $r$ selected phyla (i.e., Proteobacteria and Bacteroidetes) or K-selected phyla (i.e., Acidobacteria and Verrucomicrobia), similar to the approach of Zhou et al. (2018). These life history strategies represent bacterial taxa that grow rapidly and have high nutrient demands (r-selected) or the opposite (K-selected). We also used FUNGuild (Nguyen et al., 2016) to assign fungal ITS ASVs into functional guilds, and similar to previous studies (e.g., Veach et al., 2017), we only used sequences assigned to a single guild with a confidence of 'probable' or 'highly probable' in downstream statistical analyses. Sequences that were assigned to multiple guilds or were assigned to a guild with low confidence were not analyzed.

\subsection{Statistical analyses}

We determined effects of $R$. maximum removal treatments on bacterial and fungal $\alpha$ diversity by calculating $16 \mathrm{~S}$ and ITS Shannon diversity, Simpson diversity, and ASV richness using the 'estimate_richness' function in the phyloseq R package (McMurdie and Holmes, 2013). To identify specific bacterial and fungal ASVs that responded to $R$. maximum removal treatments, i.e., differentially abundant ASVs between treatments and controls, we used the 'exactTest' function in the edgeR R package (Robinson et al., 2010). To determine effects of treatments on $\alpha$ diversity indices and relative abundances of specific bacterial and fungal taxa and functional groups, we used linear models ('lm' function). To assess assumptions of normality of residuals of our models, we used Shapiro-Wilk tests, and when models did not meet assumptions of normality, we verified ' $1 \mathrm{~m}$ ' results using generalized linear models ('glm' function with Gamma distribution and log-link function).

We determined effects of $R$. maximum removal treatments on bacterial and fungal community composition using permutational analysis of variance (PERMANOVA) and visualized patterns in community composition using non-metric multidimensional scaling (NMDS). PERMANOVA and NMDS were conducted using Bray-Curtis distance matrices with the 'adonis2' and 'metaMDS' functions in the vegan $\mathrm{R}$ package, respectively (Oksanen et al., 2019). To determine relationships of soil variables with microbial community composition, we correlated soil variables with NMDS ordination scores using the 'envfit' function in the vegan $\mathrm{R}$ package.

For all statistical analyses on post-treatment samples, we included both 'treatment' and 'sampling month' as fixed effects in our statistical models. However, for visualization purposes, we only show treatment comparisons to illustrate effects of $R$. maximum removal, as 'sampling month' was rarely found to have significant influence on community metrics. All statistical analyses were performed in R ( $\mathrm{R}$ Core Development Team, 2019).

\section{Results}

\subsection{Effects on bacterial and fungal $\alpha$ diversity and community composition}

As expected, microbial community composition did not differ among treatments prior to treatment implementation (Fig. S1, S2). Therefore, we focus all additional analyses on the post-treatment samples. In posttreatment communities, $\alpha$ diversity indices did not differ among $R$. maximum removal treatments - there were no evident differences in bacterial or fungal Shannon diversity among treatments (Fig. 1A, B). Bacterial and fungal ASV richness and evenness (i.e., Simpson index) also did not differ among treatments (Table S2, S3). In contrast, $R$. maximum removal did affect both bacterial and fungal community composition (i.e., $\beta$ diversity, PERMANOVA analysis) (Fig. 2A, B). For both bacteria and fungi, soils exposed to canopy and forest floor removal (CFFR) clustered distinctly from other treatments on NMDS ordinations (Fig. 2A, B). Bacterial community composition was significantly correlated with soil $\mathrm{pH}$ and weakly correlated with dissolved inorganic $\mathrm{N}$ (i. e., DIN, $\mathrm{NH}_{4}^{+}+\mathrm{NO}_{3}^{-}$) (Fig. $2 \mathrm{~A}$ ) while fungal community composition was significantly correlated with DIN (Fig. 2B).

\subsection{Effects on bacterial phyla and fungal classes}

The most abundant bacterial phyla in our soils were Acidobacteria and Proteobacteria, which accounted for $35 \%$ and $33 \%$ of all sequences, respectively (Fig. 3A). Other phyla comprising $>1 \%$ of sequences included Verrucomicrobia (8.4\%), Planctomycetes (8.3\%), Actinobacteria (4.4\%), Bacteroidetes (3.6\%) and Chloroflexi (1.5\%) (Fig. 3A). Rhododendron maximum removal had no effect on the relative abundances of any bacterial phyla (all $P>0.05$ ). Further, $R$. maximum removal had no apparent effects on specific bacterial functional groups for example, ratios of $\mathrm{r}$ - vs K-selected bacterial phyla were not influenced by removal treatments ( $P=0.71$, Table $S 4)$. In addition, nitrifying bacteria (i.e., Nitrospirae) were rare, comprising only $0.2 \%$ of sequences overall, and relative abundances of nitrifiers were not influenced by R. maximum removal ( $P=0.35$, Table S4)

The most abundant fungal classes were Agaricomycetes and Mortierellomycetes, which accounted for $37 \%$ and $22 \%$ of all sequences, respectively (Fig. 3B). Other classes comprising $>1 \%$ of sequences included Archaeorhizomycetes (13.2\%), Leotiomycetes (4.8\%), Tremellomycetes (3.3\%), Sordariomycetes (1.4\%), Geminibasidiomycetes (1.3\%), Saccharomycetes (1.2\%), and Eurotiomycetes (1.1\%) (Fig. 3B). Rhododendron maximum removal did not have significant effects on the relative abundances of any fungal classes (all $P>0.05$, Fig. 3B).

\subsection{Differentially abundant bacterial and fungal ASVs}

We identified 147 bacterial ASVs to be differentially abundant between REF and R. maximum removal treatments (edgeR exactTest $P<$ 0.05 ), $39 \%$ of which belonged to Acidobacteria and $37 \%$ of which 

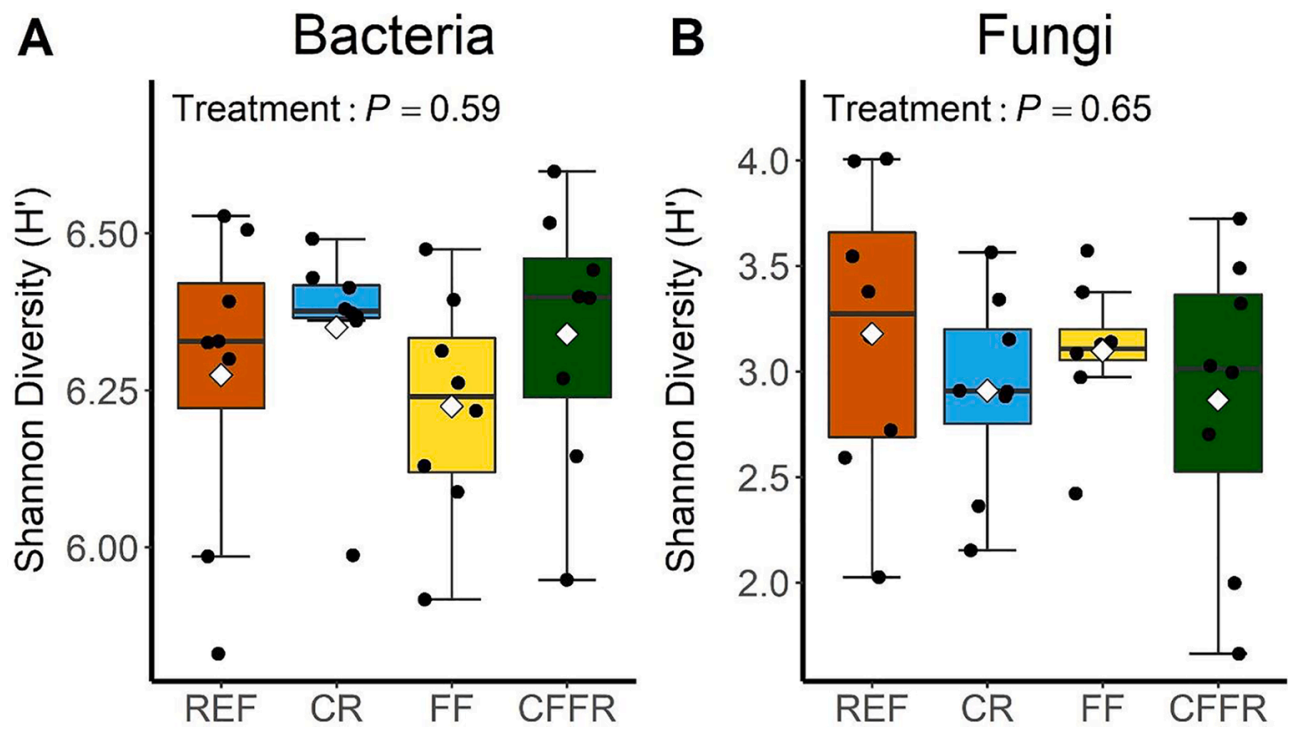

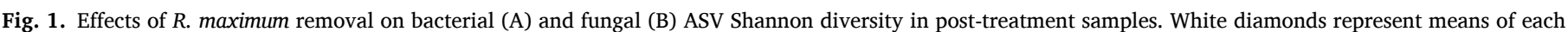

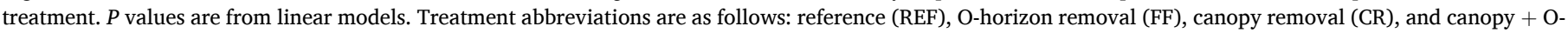
horizon removal (CFFR).
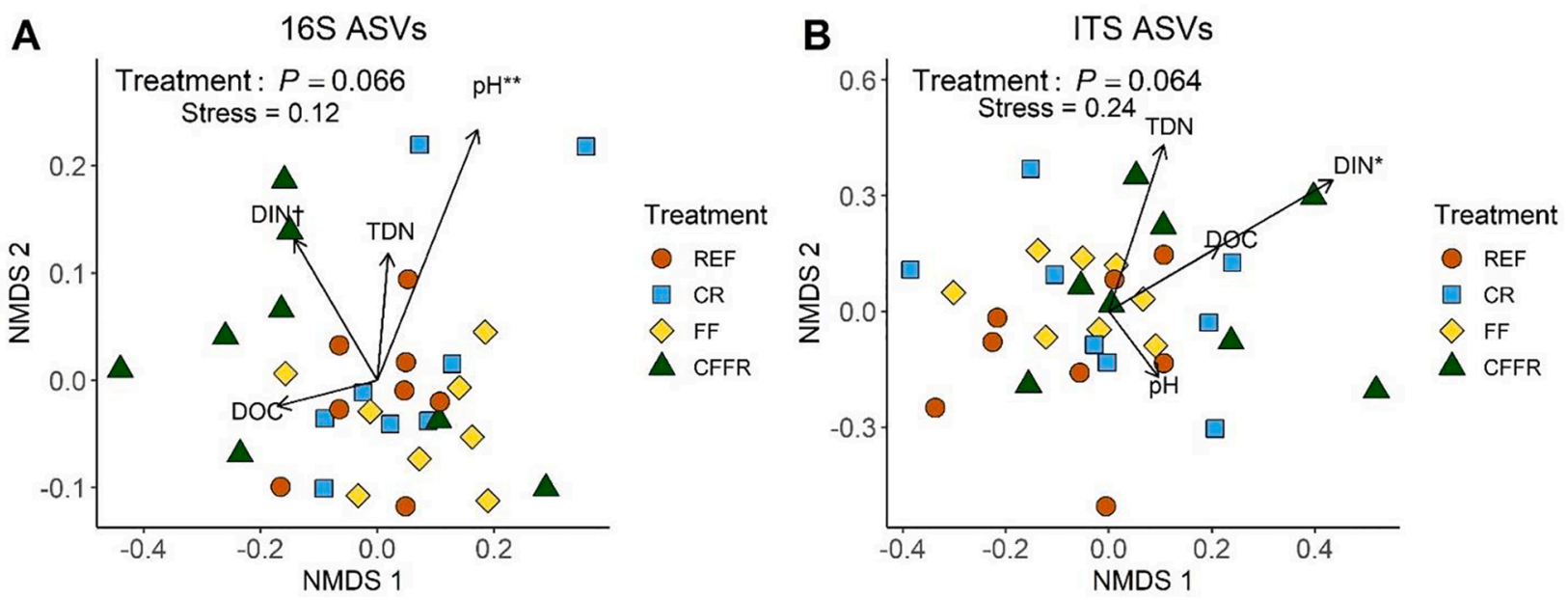

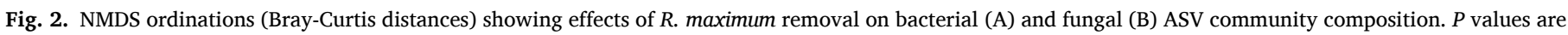

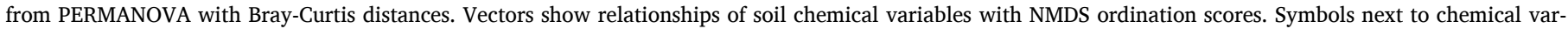

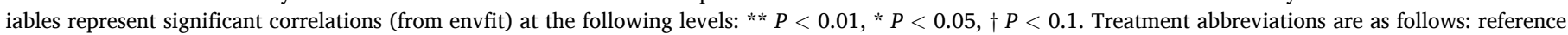
(REF), O-horizon removal (FF), canopy removal (CR), and canopy + O-horizon removal (CFFR).

belonged to Proteobacteria (Table S5). We subset the data to only include these differentially abundant taxa and analyzed relative abundance patterns of these responsive ASVs at the phylum level. Many significant positive $R$. maximum removal responses were evident at the phylum level for differentially abundant bacterial ASVs, particularly in the canopy and forest floor removal treatment (CFFR). For example, Planctomycetes were 3.6-fold more abundant in CFFR soils relative to REF soils within this differentially abundant ASV data set (Fig. 4). Further, differentially abundant Actinobacteria, Cyanobacteria, Chlamydiae, and candidate division FCPU426 accounted for $\sim 0.5-3 \%$ of sequences in CFFR, while these ASVs were not detected in REF soils (Fig. 4). Negative responses of microbial taxa to R. maximum removal were also evident for some bacterial phyla within the differentially abundant ASV data set; for example, differentially abundant Proteobacteria were $\sim 76 \%$ more abundant in REF soils than in CFFR soils and Bacteroidetes were $\sim 150 \%$ more abundant in REF soils than in CFFR soils (Fig. 4).

We identified 37 fungal ASVs to be differentially abundant between
REF and R. maximum removal soils, $79 \%$ of which belonged to Agaricomycetes and $21 \%$ of which belonged to Archaeorhizomycetes (Table S6). Class-level analyses of these responsive fungal taxa revealed significant negative $R$. maximum removal responses of Archaeorhizozmycetes, which were $\sim 4$.6-fold more abundant in REF soils compared with CFFR soils within the differentially abundant ASV data set (Fig. 4).

\subsection{Fungal functional guilds}

Of the fungal ASVs across all samples confidently assigned to single functional guild, $62 \%$ were categorized as ectomycorrhizae, $25 \%$ were categorized as soil saprotrophs, $10 \%$ were classified as undefined saprotrophs, and $1.6 \%$ were classified as endophytes, while all other guilds accounted for $<1 \%$ of classified sequences (Table S7). Relative abundances of many guilds exhibited significant effects of $R$. maximum removal, particularly mycorrhizal taxa. These effects included negative responses of ericoid mycorrhizae, which accounted for $\sim 0.3 \%$ of 

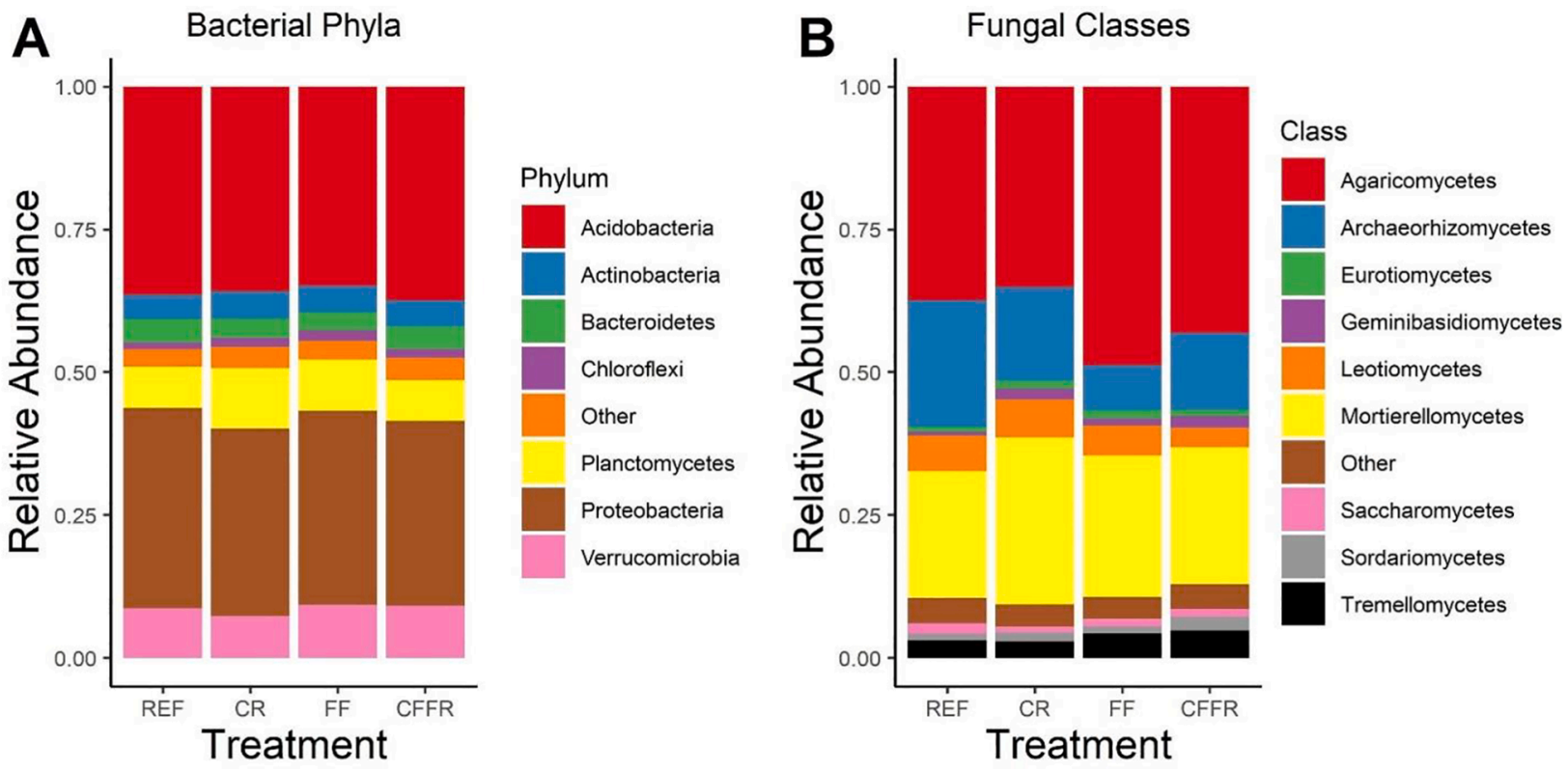

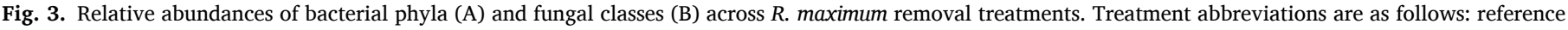
(REF), O-horizon removal (FF), canopy removal (CR), and canopy + O-horizon removal (CFFR).

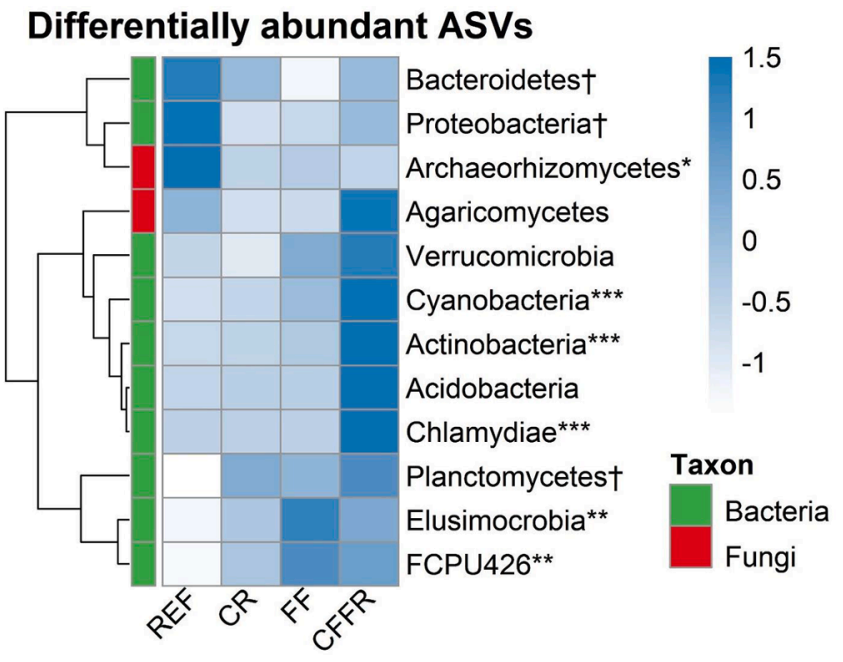

Fig. 4. Heat map showing scaled Z-scores for relative abundances of bacterial phyla and fungal classes for the 147 differentially abundant bacterial ASVs and 37 differentially abundant fungal ASVs identified by edgeR. Symbols next to taxa represent significant treatment effects (from linear models) at the following levels: $* * * P<0.001, * * P<0.01, * P<0.05, \dagger P<0.1$. The dendrogram on the heatmap reflects similarity of relative abundance patterns of taxa across $R$. maximum removal treatments (complete-linkage clustering) and does not reflect phylogenetic relationships. Treatment abbreviations are as follows: reference (REF), O-horizon removal (FF), canopy removal (CR), and canopy + O-horizon removal (CFFR)

sequences in REF soils but only $\sim 0.07-0.28 \%$ of sequences in $R$. maximum removal treatments (Fig. 5). In contrast, arbuscular mycorrhizae, orchid mycorrhizae, and wood saprotrophs all exhibited positive responses to $R$. maximum removal (Fig. 5). On average, arbuscular mycorrhizae accounted for $0.6 \%$ of sequences in removal treatments and only $0.06 \%$ in REF soils, orchid mycorrhizae accounted for $0.45 \%$ of sequences in removal treatments and only $0.2 \%$ in REF soils, and wood saprotrophs accounted for $0.13 \%$ of sequences in removal treatments and only $0.09 \%$ in REF soils (Fig. 5). Mycorrhizal taxa also exhibited some seasonal variability, with both arbuscular and orchid

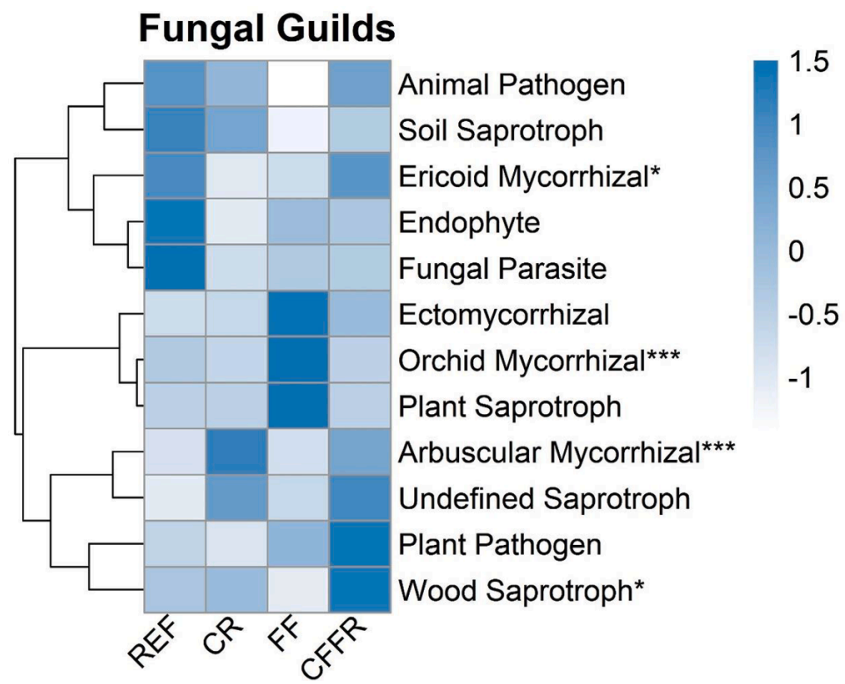

Fig. 5. Heat map showing scaled Z-scores for relative abundances of fungal functional guilds identified by FUNGuild. Symbols next to guilds represent significant treatment effects (linear models) at the following levels: $* * * P<$ $0.001,{ }^{*} P<0.05$. The dendrogram on the heatmap reflects similarity of relative abundance patterns of fungal guilds across $R$. maximum removal treatments (complete-linkage clustering). Treatment abbreviations are as follows: reference (REF), O-horizon removal (FF), canopy removal (CR), and canopy + Ohorizon removal (CFFR).

mycorrhizae exhibiting greater relative abundance in the summer relative to spring (Table S8).

\section{Discussion}

Effects of $R$. maximum removal on soil microbial communities were minor - we observed no changes in bacterial or fungal $\alpha$ diversity, no significant changes in relative abundances of bacterial and fungal taxa, and no changes in relative abundances of specific bacterial functional groups. Further, effects of removal treatments on bacterial and fungal community composition at the ASV level were subtle $(P<0.1)$ and only 
evident for the canopy plus forest floor removal treatment. These results are similar to a $R$. ponticum removal experiment in the UK, which reported no changes in microbial community structure (Jones et al., 2019), but contrast with a prior study from these same soils, which showed significant increases in microbial biomass and activities of microbial extracellular enzymes following $R$. maximum removal (Osburn et al., 2018). Together, these results suggest that $R$. maximum removal in the southern Appalachians is more likely to influence soil microbial activity than soil microbial community structure, at least in the short term.

Though microbial community composition responses to R. maximum removal were minor overall, edgeR analysis did identify multiple specific bacterial and fungal ASVs that were responsive to removals, i.e., differentially abundant sequences. However, these responsive taxa comprised only $\sim 1.9 \%$ (147 of 7,875) of detected bacterial ASVs and only $\sim 2.4 \%$ (37 of 1,530) of fungal ASVs, while all other taxa were unresponsive, further highlighting the subtle responses of microbial communities to R. maximum removal. Despite their rarity, the responsive ASVs exhibited significant patterns across treatments at high taxonomic levels. For example, ASVs responding positively to $R$. maximum removal were found in Actinobacteria and Planctomycetes, while negatively responding ASVs clustered in Proteobacteria and Bacteroidetes. This result is surprising given that Proteobacteria and Bacteroidetes are commonly classified as r-selected (Fierer et al., 2007; Zhou et al., 2018) and the increases in soil $\mathrm{C}$ and $\mathrm{N}$ following $R$. maximum removal would be expected to favor these rapidly growing taxa. This unexpected pattern is likely attributed to the small number of differentially abundant Bacteroidetes and Proteobacteria detected (5 and 26 ASVs, respectively); these particular ASVs apparently do not exhibit the life history strategies typical of their phyla. Further, phylum-level patterns in differentially abundant ASVs were observed primarily in the canopy + forest floor removal (CFFR) treatment, similar to patterns in community composition at the ASV level, which were also primarily evident in CFFR. This is in agreement with our prior study, which showed increased soil $\mathrm{C}$ and $\mathrm{N}$, increased microbial biomass, and increased extracellular enzyme activities in CFFR but not in canopy removal (CR) or forest floor removal (FF) alone (Osburn et al., 2018). Overall, these results suggest that bulk soil microbial communities will respond to $R$. maximum removal only when canopy and forest floor removal are combined, likely due to mobilization of organic $\mathrm{C}$ and $\mathrm{N}$ in the soil by prescribed fire and simultaneous die-back of $R$. maximum roots and their functionally dominant mycorrhizal symbionts following mechanical cutting of shrubs.

Our study also reveals clear responses of several key fungal functional groups to R. maximum removal. For example, ericoid mycorrhizae declined in relative abundance following treatments, indicating that removals successfully inhibited activity of $R$. maximum roots and their mycorrhizal symbionts. In addition, orchid mycorrhizae and arbuscular mycorrhizae increased in abundance following removals, which reflects the increased diversity and cover of herbaceous vegetation and increased density of tree seedlings previously reported for these R. maximum removal plots (Elliott and Miniat, 2018). Relative abundance of wood saprotrophs also increased following removals, which may reflect increased availability of dead woody $R$. maximum root or stem material in plots where $R$. maximum was cut. Further, the increases in arbuscular mycorrhizae and wood saprotrophs may be responsible for the increases in hydrolytic extracellular enzyme activities we previously observed in these plots (Osburn et al., 2018), as these groups of fungi are known producers of carbon- and nutrient-acquiring enzymes (Burke et al., 2011; Smith and Read, 2010). Overall, it is clear that vegetation changes following R. maximum removal will manifest in altered abundances of key fungal functional groups, which will likely influence soil biogeochemical functions and forest recovery following removal treatments.

In addition to vegetation influences, effects on soil microbial communities are likely mechanistically linked to changes in soil properties that occur following R. maximum removal treatments. For example, DIN increased following $R$. maximum removal and was also significantly correlated with both bacterial and fungal community structure, suggesting that DIN may have driven some of the microbial community responses we observed. The importance of soil properties in structuring microbial communities may also explain the lack of stronger microbial responses to $R$. maximum removal. For example, removals did not influence soil $\mathrm{pH}$, which is known to have strong influence on microbial communities across biomes (Fierer and Jackson, 2006) and in Appalachian forests specifically (Osburn et al., 2019), and was also significantly correlated with bacterial community composition in the present study. This lack of a soil $\mathrm{pH}$ response may be attributed to the short-term nature of this study - over longer time scales, increased abundance of herbaceous vegetation and trees with higher $\mathrm{pH}$ litter than $R$. maximum (e.g., Acer rubrum, Liriodendron tulipifera) may result in increased soil $\mathrm{pH}$, which will likely influence microorganisms, particularly bacterial communities. Indeed, prior studies from the Coweeta Basin have shown clear long-term (i.e., multi-decadal) effects of management activities and associated vegetation changes on soil $\mathrm{pH}$ and microbial communities (Osburn et al., 2019), suggesting that long-term effects of $R$. maximum removal on soil microorganisms are likely to occur.

In the short term, $R$. maximum removal appears successful for promoting recovery of southern Appalachian forests that have experienced eastern hemlock declines. Removals stimulate microbial biogeochemical activity (Osburn et al., 2018), thereby increasing availability of soil nutrients to hardwood tree seedlings, which are abundant in the seedbank (Cofer et al., 2018) and thus increase in density following treatments (Elliott and Miniat, 2018). Here, we show that these vegetation and biogeochemical responses occur in the absence of large changes to soil microbial communities and that the microbial responses we did see (i.e., mycorrhizal fungi) appear closely linked to vegetation changes. Further, the apparent stability of microbial communities may actually be beneficial for the maintenance of forest ecosystem services following $R$. maximum removal. For example, a nearby study showed that canopy removal alone (CR) and in combination with forest floor removal (CFFR) did not degrade water quality, including no increases in stream $\mathrm{NO}_{3}^{-}$ (Elliott and Miniat, 2020), which may be attributed to the lack of response of nitrifying bacteria in riparian soil observed here. However, continued changes in vegetation and associated soil properties will potentially drive larger changes to soil microbial communities in the long term, highlighting the importance of continual monitoring of these ecosystems in the years following management activities.

\section{Conclusions}

In the wake of eastern hemlock decline, Rhododendron maximum is emerging as a foundation species in Appalachian ecosystems (Dudley et al., 2020); it is expanding its habitat, which has numerous implications for the physical structure and biogeochemical functions of Appalachian forests. To restore these forests, aggressive $R$. maximum management strategies (i.e., removals) will be necessary. Here, we show that $R$. maximum removal has generally minor effects on microbial community structure in the short term. However, responses of some key microbial functional groups (i.e., mycorrhizal fungi) were evident, suggesting that the microbial responses that do take place will contribute to forest recovery. Further, though long-term effects of $R$. maximum removal are difficult to predict, it is possible that sustained vegetation changes will drive larger changes to soil microbial communities in the future. Therefore, continued monitoring is necessary to evaluate the efficacy of $R$. maximum removal for restoring forest structure while maintaining the critical services that Appalachian ecosystems provide.

\section{Declaration of Competing Interest}

The authors declare that they have no known competing financial 
interests or personal relationships that could have appeared to influence the work reported in this paper.

\section{Acknowledgements}

This project was supported by the Coweeta LTER, funded by National Science Foundation grant DEB-1637522. We thank the Coweeta Hydrologic Laboratory, Southern Research Station, USDA Forest Service for support and the USDA Forest Service Nantahala Ranger District staff, Nantahala National Forest, for executing the treatments. We also thank Bobbie Niederlehner for help with soil chemistry analyses. The use of trade or firm names in this publication is for reader information and does not imply endorsement by the U.S. Department of Agriculture of any product or service.

\section{Appendix A. Supplementary data}

Supplementary data to this article can be found online at https://doi. org/10.1016/j.foreco.2021.119398.

\section{References}

Abarenkov, K., Nilsson, R.H., Larsson, K.-H., Alexander, I.J., Eberhardt, U., Erland, S., Høiland, K., Kjøller, R., Larsson, E., Pennanen, T., Sen, R., Taylor, A.F.S., Tedersoo, L., Ursing, B.M., Vrålstad, T., Liimatainen, K., Peintner, U., Kõljalg, U., 2010. The UNITE database for molecular identification of fungi - recent updates and future perspectives. New Phytol. 186, 281-285.

Apprill, A., McNally, S., Parsons, R., Weber, L., 2015. Minor revision to V4 region SSU rRNA 806R gene primer greatly increases detection of SAR11 bacterioplankton. Aquat. Microb. Ecol. 75, 129-137. https://doi.org/10.3354/ame01753.

Ball, B.A., Hunter, M.D., Kominoski, J.S., Swan, C.M., Bradford, M.A., 2008 Consequences of non-random species loss for decomposition dynamics: experimental evidence for additive and non-additive effects. J. Ecol. 96, 303-313. https://doi.org/ 10.1111/j.1365-2745.2007.01346.x.

Beckage, B., Clark, J.S., Clinton, B.D., Haines, B.L., 2000. A long-term study of tree seedling recruitment in southern Appalachian forests: the effects of canopy gaps and shrub understories. Canadian Journal of Forest Research 30, 1617-1631. https:// doi.org/10.1139/cjfr-30-10-1617.

Bellemain, E., Carlsen, T., Brochmann, C., Coissac, E., Taberlet, P., Kauserud, H., 2010. ITS as an environmental DNA barcode for fungi: an in silico approach reveals potential PCR biases. BMC Microbiol. 10, 189. https://doi.org/10.1186/1471-218010-189.

Boerner, R.E.J., Giai, C., Huang, J., Miesel, J.R., 2008. Initial effects of fire and mechanical thinning on soil enzyme activity and nitrogen transformations in eight North American forest ecosystems. Soil Biol. Biochem. 40, 3076-3085. https://doi. org/10.1016/j.soilbio.2008.09.008.

Bolstad, P.V., Elliot, K.J., Miniat, C.F., 2018. Forests, shrubs, and terrain: top-down and bottom-up controls on forest structure. Ecosphere 9, e02185. https://doi.org/ $10.1002 /$ ecs 2.2185 .

Bolyen, E., Rideout, J.R., Dillon, M.R., Bokulich, N.A., Abnet, C., Al-Ghalith, G.A., Alexander, H., Alm, E.J., Arumugam, M., Asnicar, F., Bai, Y., Bisanz, J.E., Bittinger, K., Brejnrod, A., Brislawn, C.J., Brown, C.T., Callahan, B.J., Caraballo-Rodríguez, A. M., Chase, J., Cope, E., Silva, R.D., Dorrestein, P.C., Douglas, G.M., Durall, D.M., Duvallet, C., Edwardson, C.F., Ernst, M., Estaki, M., Fouquier, J., Gauglitz, J.M., Gibson, D.L., Gonzalez, A., Gorlick, K., Guo, J., Hillmann, B., Holmes, S., Holste, H., Huttenhower, C., Huttley, G., Janssen, S., Jarmusch, A.K., Jiang, L., Kaehler, B., Kang, K.B., Keefe, C.R., Keim, P., Kelley, S.T., Knights, D., Koester, I., Kosciolek, T., Kreps, J., Langille, M.G., Lee, J., Ley, R., Liu, Y.-X., Loftfield, E., Lozupone, C., Maher, M., Marotz, C., Martin, B.D., McDonald, D., McIver, L.J., Melnik, A.V., Metcalf, J.L., Morgan, S.C., Morton, J., Naimey, A.T., Navas-Molina, J.A., Nothias, L. F., Orchanian, S.B., Pearson, T., Peoples, S.L., Petras, D., Preuss, M.L., Pruesse, E., Rasmussen, L.B., Rivers, A., Michael S Robeson, I.I., Rosenthal, P., Segata, N., Shaffer, M., Shiffer, A., Sinha, R., Song, S.J., Spear, J.R., Swafford, A.D., Thompson, L.R., Torres, P.J., Trinh, P., Tripathi, A., Turnbaugh, P.J., Ul-Hasan, S., Hooft, J.J. van der, Vargas, F., Vázquez-Baeza, Y., Vogtmann, E., Hippel, M. von, Walters, W., Wan, Y., Wang, M., Warren, J., Weber, K.C., Williamson, C.H., Willis, A.D., Xu, Z.Z., Zaneveld, J.R., Zhang, Y., Zhu, Q., Knight, R., Caporaso, J.G., 2018. QIIME 2: Reproducible, interactive, scalable, and extensible microbiome data science. PeerJ. https://doi.org/10.7287/peerj.preprints.27295v2.

Burke, D.J., Weintraub, M.N., Hewins, C.R., Kalisz, S., 2011. Relationship between soil enzyme activities, nutrient cycling and soil fungal communities in a northern hardwood forest. Soil Biol. Biochem. 43, 795-803. https://doi.org/10.1016/j. soilbio. 2010.12.014.

Callahan, B.J., McMurdie, P.J., Rosen, M.J., Han, A.W., Johnson, A.J.A., Holmes, S.P., 2016. DADA2: High-resolution sample inference from Illumina amplicon data. Nat Methods 13, 581-583. https://doi.org/10.1038/nmeth.3869.

Clinton, B.D., 2003. Light, temperature, and soil moisture responses to elevation, evergreen understory, and small canopy gaps in the southern Appalachians. For. Ecol. Manag. 186, 243-255. https://doi.org/10.1016/S0378-1127(03)00277-9.
Cofer, T.M., Elliott, K.J., Bush, J.K., Miniat, C.F., 2018. Rhododendron maximum impacts seed bank composition and richness following Tsuga canadensis loss in riparian forests. Ecosphere 9, e02204. https://doi.org/10.1002/ecs2.2204.

Dudley, M.P., Freeman, M., Wenger, S., Jackson, C.R., Pringle, C.M., 2020. Rethinking foundation species in a changing world: The case for Rhododendron maximum as an emerging foundation species in shifting ecosystems of the southern Appalachians. Forest Ecology and Management 472, 118240. https://doi.org/10.1016/j. foreco.2020.118240.

Elliott, K.J., Miniat, C.F., 2020. Removing riparian Rhododendron maximum in postTsuga canadensis riparian forests does not degrade water quality in southern Appalachian streams. Science of The Total Environment 143270. https://doi.org/ 10.1016/j.scitotenv. 2020.143270.

Elliott, K.J., Miniat, C.F., 2018. Herbaceous-layer diversity and tree seedling recruitment are enhanced following Rhododendron maximum shrub removal. For. Ecol. Manag. 430, 403-412. https://doi.org/10.1016/j.foreco.2018.08.016.

Elliott, K.J., Vose, J.M., 2012. Age and distribution of an evergreen clonal shrub in the Coweeta Basin: Rhododendron maximum L. The Journal of the Torrey Botanical Society 139, 149-166.

Falkowski, P.G., Fenchel, T., Delong, E.F., 2008. The Microbial Engines That Drive Earth's Biogeochemical Cycles. Science 320, 1034-1039. https://doi.org/10.1126/ science.1153213.

Fierer, N., 2017. Embracing the unknown: disentangling the complexities of the soil microbiome. Nat. Rev. Microbiol. 15, 579-590. https://doi.org/10.1038/ nrmicro.2017.87.

Fierer, N., Bradford, M.A., Jackson, R.B., 2007. Toward an ecological classification of soil bacteria. Ecology 88, 1354-1364.

Fierer, N., Jackson, R.B., 2006. The diversity and biogeography of soil bacterial communities. Proc. Natl. Acad. Sci. U.S.A. 103, 626-631. https://doi.org/10.1073/ pnas. 0507535103.

Ford, C.R., Elliott, K.J., Clinton, B.D., Kloeppel, B.D., Vose, J.M., 2012. Forest dynamics following eastern hemlock mortality in the southern Appalachians. Oikos 121, 523-536. https://doi.org/10.1111/j.1600-0706.2011.19622.x.

Giai, C., Boerner, R.E.J., 2007. Effects of ecological restoration on microbial activity, microbial functional diversity, and soil organic matter in mixed-oak forests of southern Ohio, USA. Applied Soil Ecology 35, 281-290. https://doi.org/10.1016/j. apsoil.2006.08.003.

Hunter, M.D., Adl, S., Pringle, C.M., Coleman, D.C., 2003. Relative effects of macroinvertebrates and habitat on the chemistry of litter during decomposition. Pedobiologia 47, 101-115. https://doi.org/10.1078/0031-4056-00174.

Jones, G.L., Scullion, J., Allison, G., Stott, H., Johnson, D., Owen, R., Williams, G., Gwynn-Jones, D., 2019. Reduced soil respiration beneath invasive Rhododendron ponticum persists after cutting and is related to substrate quality rather than microbial community. Soil Biology Biochemistry 138, 107577. https://doi.org/ 10.1016/j.soilbio.2019.107577.

Laseter, S.H., Ford, C.R., Vose, J.M., Swift, L.W., 2012. Long-term temperature and precipitation trends at the Coweeta Hydrologic Laboratory, Otto, North Carolina. USA. Hydrol. Res. 43, 890-901. https://doi.org/10.2166/nh.2012.067.

McDonald, D., Price, M.N., Goodrich, J., Nawrocki, E.P., DeSantis, T.Z., Probst, A., Andersen, G.L., Knight, R., Hugenholtz, P., 2012. An improved Greengenes taxonomy with explicit ranks for ecological and evolutionary analyses of bacteria and archaea. ISME J 6, 610-618. https://doi.org/10.1038/ismej.2011.139.

McMurdie, P.J., Holmes, S., 2013. phyloseq: An R Package for Reproducible Interactive Analysis and Graphics of Microbiome Census Data. PLOS ONE 8, e61217. https:// doi.org/10.1371/journal.pone.0061217.

Nguyen, N.H., Song, Z., Bates, S.T., Branco, S., Tedersoo, L., Menke, J., Schilling, J.S., Kennedy, P.G., 2016. FUNGuild: An open annotation tool for parsing fungal community datasets by ecological guild. Fungal Ecol. 20, 241-248. https://doi.org/ 10.1016/j.funeco.2015.06.006.

Nilsen, E.T., Clinton, B.D., Lei, T.T., Miller, O.K., Semones, S.W., Walker, J.F., 2001. Does Rhododendron maximum L. (Ericaceae) Reduce the Availability of Resources Above and Belowground for Canopy Tree Seedlings? The American Midland Naturalist 145, 325-343. https://doi.org/10.1674/0003-0031(2001)145[0325:DRMLER]2.0.CO;2.

Oksanen, J., Blanchet, F.G., Friendly, M., Kindt, R., Legendre, P., McGlinn, D., Minchin, P.R., O'Hara, R.B., Simpson, G.L., Solymos, P., Stevens, M.H.H., Szoecs, E., Wagner, H., 2019. vegan: Community Ecology Package.

Osburn, E.D., Elliottt, K.J., Knoepp, J.D., Miniat, C.F., Barrett, J.E., 2018. Soil microbial response to Rhododendron understory removal in southern Appalachian forests: Effects on extracellular enzymes. Soil Biol. Biochem. 127, 50-59. https://doi.org/ 10.1016/j.soilbio.2018.09.008.

Osburn, E.D., McBride, S.G., Aylward, F.O., Badgley, B.D., Strahm, B.D., Knoepp, J.D., Barrett, J.E., 2019. Soil Bacterial and Fungal Communities Exhibit Distinct LongTerm Responses to Disturbance in Temperate Forests. Front. Microbiol. 10 https:// doi.org/10.3389/fmicb.2019.02872.

Parada, A.E., Needham, D.M., Fuhrman, J.A., 2016. Every base matters: assessing small subunit rRNA primers for marine microbiomes with mock communities, time series and global field samples. Environ. Microbiol. 18, 1403-1414. https://doi.org/ 10.1111/1462-2920.13023.

Pedregosa, F., Varoquaux, G., Gramfort, A., Michel, V., Thirion, B., Grisel, O., Blondel, M., Prettenhofer, P., Weiss, R., Dubourg, V., Vanderplas, J., Passos, A., Cournapeau, D., Brucher, M., Perrot, M., Duchesnay, É., 2011. Scikit-learn: Machine Learning in Python. J. Mach. Learn. Res. 12, 2825-2830.

R Core Development Team, 2019. R: A Language and Environment for Statistical Computing. R Foundation for Statistical Computing, Vienna, Austria.

Robinson, M.D., McCarthy, D.J., Smyth, G.K., 2010. edgeR: a Bioconductor package for differential expression analysis of digital gene expression data. Bioinformatics 26 , 139-140. https://doi.org/10.1093/bioinformatics/btp616. 
Shen, Y., Cheng, R., Xiao, W., Yang, S., Guo, Y., Wang, N., Zeng, L., Lei, L., Wang, X., 2018. Labile organic carbon pools and enzyme activities of Pinus massoniana plantation soil as affected by understory vegetation removal and thinning. Sci. Rep. 8, 573. https://doi.org/10.1038/s41598-017-18812-x.

Smith, S.E., Read, D.J., 2010. Mycorrhizal Symbiosis. Academic Press.

Thomas, D., 1996. Soil Survey of Macon County, North Carolina. USDA, Natural Resources Conservation Service, Washington, DC, USA.

USDA, 2011. Nantahala Pisgah NF Forest Plan Amendments: Prescribed fire amendment 26 [WWW Document]. URL https://www.fs.usda.gov/Internet/FSE_DOCUMENTS/ stelprdb5346291.pdf (accessed 4.30.18).

Veach, A.M., Stokes, C.E., Knoepp, J., Jumpponen, A., Baird, R., 2017. Fungal Communities and Functional Guilds Shift Along an Elevational Gradient in the Southern Appalachian Mountains. Microb. Ecol. https://doi.org/10.1007/s00248017-1116-6.

Vose, J.M., Wear, D.N., Mayfield, A.E., Dana Nelson, C., 2013. Hemlock woolly adelgid in the southern Appalachians: Control strategies, ecological impacts, and potential management responses. For. Ecol. Manag. 291, 209-219. https://doi.org/10.1016/j. foreco.2012.11.002.

Wright, C.J., Coleman, D.C., 2002. Responses of soil microbial biomass, nematode trophic groups, $\mathrm{N}$-mineralization, and litter decomposition to disturbance events in the southern Appalachians. Soil Biol. Biochem. 34, 13-25. https://doi.org/10.1016/ S0038-0717(01)00128-6.

Wu, J., Liu, Z., Wang, X., Sun, Y., Zhou, L., Lin, Y., Fu, S., 2011. Effects of understory removal and tree girdling on soil microbial community composition and litter decomposition in two Eucalyptus plantations in South China. Functional Ecology 25, 921-931. https://doi.org/10.1111/j.1365-2435.2011.01845.x.

Wurzburger, N., Hendrick, R.L., 2009. Plant litter chemistry and mycorrhizal roots promote a nitrogen feedback in a temperate forest. J. Ecol. 97, 528-536. https://doi. org/10.1111/j.1365-2745.2009.01487.x.

Wurzburger, N., Hendrick, R.L., 2007. Rhododendron thickets alter N cycling and soil extracellular enzyme activities in southern Appalachian hardwood forests. Pedobiologia 50, 563-576. https://doi.org/10.1016/j.pedobi.2006.10.001.

Zhao, J., Wang, X., Shao, Y., Xu, G., Fu, S., 2011. Effects of vegetation removal on soil properties and decomposer organisms. Soil Biol. Biochem. 43, 954-960. https://doi. org/10.1016/j.soilbio.2011.01.010.

Zhou, Z., Wang, C., Luo, Y., 2018. Effects of forest degradation on microbial communities and soil carbon cycling: A global meta-analysis. Global Ecol Biogeogr 27, 110-124. https://doi.org/10.1111/geb.12663. 